\title{
Zu Daniel.
}

Von E. Nestle.

\section{1) Dan. 9, 26.}

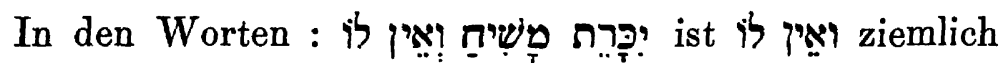

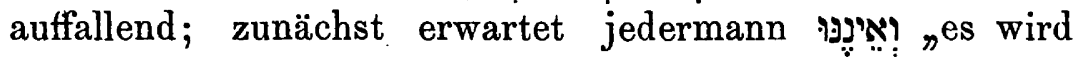
ausgerottet werden der Gesalbte (ein Gesalbter) und wird nicht mehr sein." Zum Theil wird auch so übersetzt, sei's dals man das Auffallende des Ausdrucks gar nicht bemerkt, sei es, dafs man es erklärt wie z. B. Böhl, der sagt „wörtlich : und wird mit ihm zu nichts werden; es ist

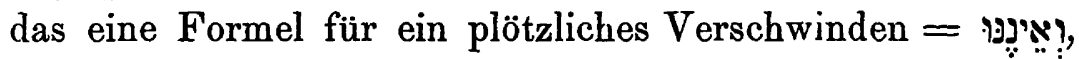
welche in der mündlichen Rede durch eine Pantomime verstärkt werden mochte (vgl. Hag. 2, 17 und auch Gen. 5, 24). ${ }^{*}$ Andere ergänzen ein Substantiv : und kein Volk wird ihm sein, oder : kein Gesalbter, d. h. kein legitimer Nachfolger; wieder Andere allgemeiner : und wird nichts mehr sein, was ihm gehört. Bemerkenswerth ist, dafs die alten Versionen das it

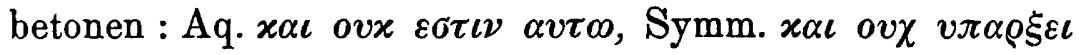

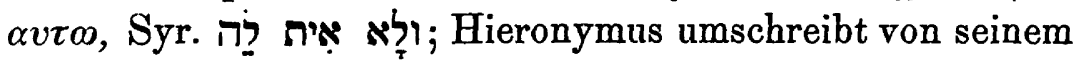
christlichen Standpunkt aus : et non erit eius populus, qui eum negaturus est. Am interessantesten ist aber die Uebersetzung des Theodotion $x \alpha \iota x \rho \iota \mu \alpha$ ovx $\varepsilon \sigma \tau \iota \nu$ [resp. $\varepsilon \sigma \tau \alpha \iota]$ $\varepsilon \nu$ $\alpha v \tau \omega$. Darin liegt nämlich, was bis jetzt nicht beachtet worden zu sein scheint, eine Anspielung auf Ezech. 21, 32

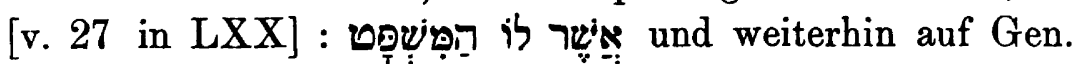
49, 10 שלו Deutung von שלו, die Schultz (A. T. Theol." 672) gegenüber dem entschiedenen Widerspruche so viel competenterer Sprachgelehrter nur sehr schüchtern festhalten will. 


\section{2) Der Greael der Verwüstung.}

Dan. 9, 27. 11, 31. 12, 11.

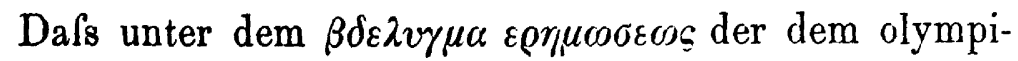
schen Zeus geweihte Altar zu verstehen sei, den Antiochus Epiphanes im Tempel zu Jerusalem aufstellen liefs, darf als ausgemacht gelten; ob auch eine Statue des Zeus dabei war, ist noch fraglich. Wie erklärt sich aber die so seltsame Bezeichnung im Buch Daniel? Nun ganz einfach :

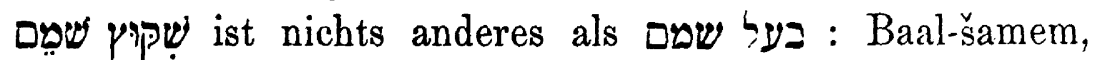
d. h. Zeus. Ich war sehr überrascht, nachdem mir diese Vermuthung aufgestofsen war, eben an der biblischen Stelle, die von diesem Thun des Antiochus berichtet, II. Makk. 6, 2, in der syrischen Bibel $Z$ בעלשמין wiedergegeben zu finden, gleichsam zur Bestätigung dieser Gleichsetzung. Nicht als ob im Daniel nun wirklich שֵָָׁ oder שu zu vocalisiren wäre; die massorethische Punktation ist vielmehr absichtliche Verketzerung und als solche beizubehalten; aber gegen $\mathrm{B} \ddot{\mathrm{a}} \mathbf{r}$ wird wenigstens an allen Stellen die defecte Schreibung von שִ vorzuziehen sein. Damit ist freilich die grammatikalisch auffallende Form (11, 31 ohne Wiederholung des Artikels) und die noch auffallendere משמיצ' $(9,27$ Plural mit Singular) nicht besser erklärt als bisher, unter solchen Umständen aber am Ende nicht mehr so verwunderlich. Ich bemerke noch, dafs neben dem häufigen aramäischen (mit Mem) inschriftlich bezeugt ist. 